\title{
The anti-IRBP IgG1 and IgG2a response does not correlate with susceptibility to experimental autoimmune uveitis
}

\section{Vieira de Moraes ${ }^{1}$, G.A. Martins ${ }^{1}$, M. Flangini ${ }^{1}$, O.M. Ibañez ${ }^{2}$, O.A. Sant'Anna ${ }^{3}$ and L.V. Rizzo $1,4,5$}

\author{
${ }^{1}$ Laboratório de Imunologia Clínica, Departamento de Imunologia, \\ Instituto de Ciências Biomédicas, Universidade de São Paulo, São Paulo, SP, Brasil \\ ${ }^{2}$ Laboratório de Imunogenética, ${ }^{3}$ Laboratório de Imunoquímica, Instituto Butantan, \\ São Paulo, SP, Brasil \\ ${ }^{4}$ Instituto de Investigação em Imunologia, Ministério da Ciência e Tecnologia, \\ Brasília, DF, Brasil \\ ${ }^{5}$ LIM-60 Disciplina de Imunologia Clínica e Alergia, \\ Departamento de Clínica Médica e Fundação Zerbini, \\ Faculdade de Medicina, Universidade de São Paulo, São Paulo, SP, Brasil
}

\author{
Correspondence \\ L.V. Rizzo \\ Departamento de Imunologia \\ ICB IV, USP \\ Av. Prof. Lineu Prestes, 1730 \\ 05508-900 São Paulo, SP \\ Brasil \\ Fax: +55-11-309-1739 \\ E-mail: Ivrizzo@icb.usp.br \\ Research supported by FAPESP and \\ CNPq. L.V. Rizzo, O.M. Ibañez and \\ O.A. Sant'Anna are recipients of \\ CNPq fellowships for scientific \\ productivity. L.V. de Moraes is \\ the recipient of a post-doctoral \\ fellowship from $\mathrm{CNPq}$. \\ $\ldots \ldots \ldots \ldots \ldots \ldots \ldots$
}

Received July 18, 2005 Accepted January 10, 2006 ..................

\begin{abstract}
Susceptibility to experimental autoimmune uveitis (EAU) in inbred mice has been associated with a dominant Th1 response. Elevated anti-inter-photoreceptor retinoid-binding protein (anti-IRBP) IgG2a/ $\mathrm{IgG1}$ antibody ratios have been implicated as candidate markers to predict disease severity. In the present study, both the anti-IRBP antibody isotype and severity of EAU phenotypes were examined in 4 non-isogenic genetically selected mouse lines to determine if they can be used as general markers of disease. Mice between 8 and 12 weeks old selected for high $\left(\mathrm{H}_{\mathrm{III}}\right)$ or low $\left(\mathrm{L}_{\mathrm{III}}\right)$ antibody response and for maximum ( $\mathrm{AIR}_{\mathrm{MAX}}$ ) or minimum ( $\left.\mathrm{AIR}_{\mathrm{MIN}}\right)$ acute inflammatory reaction (AIR) were immunized with IRBP. Each experiment was performed with at least 5 mice per group. EAU was evaluated by histopathology 21 days after immunization and the minimal criterion was inflammatory cell infiltration of the ciliary body, choroid and retina. Serum IgG1- and IgG2a-specific antibodies were determined by ELISA. EAU was graded by histological examination of the enucleated eyes. The incidence of EAU was lower in AIR $_{\text {MIN }}$ mice whereas in the other strains approximately $40 \%$ of the animals developed the disease. Low responder animals did not produce anti-IRBP IgG2a antibodies or interferon- $\gamma$. No correlation was observed between susceptibility to EAU and anti-IRBP isotype profiles. Susceptibility to EAU is related to the intrinsic capacity to mount higher inflammatory reactions and increased production of anti-IRBP IgG2a isotype is not necessarily a marker of this immunologic profile.
\end{abstract}

Key words

- Autoimmunity

- $\lg \mathrm{G} 1$ and $\lg \mathrm{G} 2 \mathrm{a}$ isotypes

- Inflammation

- Genetically selected mice

- Uveitis 


\section{Introduction}

Experimental autoimmune uveitis (EAU) is an organ-specific T cell-mediated disease that targets the neural retina and leads to retinochoroiditis and blindness. The failure of the mechanisms that maintain the state of immune tolerance in the eye can be induced in experimental models by immunization with retinal antigens such as the soluble protein S-antigen and the glycolipoprotein inter-photoreceptor retinoid-binding protein (IRBP) (1-4). EAU is a cell-mediated inflammatory disease in which the uveitogenic retinal antigen-specific $\mathrm{CD} 4^{+} \mathrm{T}$ lymphocytes invade and destroy the retina $(5,6)$. There is evidence implicating Th1-like lymphocytes in the pathogenesis of EAU, whereas induction of a Th2-like response seems to be protective (7-10). Sun et al. (11) demonstrated that susceptibility to the development of EAU is associated with a predominant Th1 response to IRBP in six different isogenic mouse strains, and that resistance to disease can occur in the presence or absence of a dominant $\mathrm{Th} 2$ response.

Several mechanisms have been implicated in the susceptibility to the development of EAU. Mutations in two genes, $l p r$ and $g l d$, result in defects in apoptosis induction in mice. These deficiencies result in inefficient elimination of autoreactive T cells and consequent accumulation of this lymphocyte population (12-15). They may have a role in ocular autoimmunity since Fas and FasL play a role in the maintenance of immunoprivilege in the eye $(16,17)$. Abnormalities during the intra- and/or extrathymic clonal T-cell selection (18) and expansion or even in the capacity of these lymphocytes to recognize ocular antigens and/or proteins that mimic ocular antigens have been associated with certain haplotypes of the major histocompatibility complex (MHC). It has been demonstrated that the MHC haplotypes $\mathrm{H}-2^{\mathrm{k}}, \mathrm{H}-2^{\mathrm{b}}$, or $\mathrm{H}-2^{\mathrm{r}}$ correlate with susceptibility to EAU in inbred mouse strains, whereas the presence of other alleles in the IE sub-region has been related to resistance $(19,20)$. The importance of the MHC is best exemplified by the individual response to the 161-180 peptide of IRBP, which contains a major epitope recognized as pathogenic by the $\mathrm{H}-2^{\mathrm{r}}$ bearing B10.RIII mice (21).

The investigation of genes controlling acquired or innate immune mechanisms has demonstrated that major immunobiological functions such as inflammatory responses, quantitative antibody production, immunological tolerance, and $\mathrm{T}$ cell-mediated reactivity, in spite of their functional integration are, at least in part, under the additive effect of independent segregating loci (22-25). The resulting polymorphic regulation of innate and adaptive immunity is the fundamental characteristic ensuring the survival of a genetically heterogeneous natural population. This variability is related to the genotypes of the population and the environmental conditions to which the individuals are subjected before and after birth.

To better understand the influence of a complex genetic background intervening in the innate and/or adaptive immune functions on EAU development and to establish the possible association of specific anti-IRBP isotype profiles in the susceptibility to developing disease, the present study was carried out in genetically selected lineages of mice for high $(\mathrm{H})$ or low $(\mathrm{L})$ antibody responses (26) and for maximal or minimal acute inflammatory reactions ( $\mathrm{AIR}_{\mathrm{MAX}}$ and $\mathrm{AIR}_{\mathrm{MIN}}$, respectively) (23). As pointed out by Boyartchuk and Dietrich (27), the plasticity and redundancy of the immune system complicate the experimental study of these distinct components. Nevertheless, the goal of genetic selection is to create mouse lineages with extreme and easily differentiated phenotypes. If the selected genes modify the immune function, the responsiveness to selfantigens or toxins and infectious agents can also be modified. Thus, the opposite capacity of the independent genetically modified 
mice to establish protective mechanisms reflects a dynamic relationship between gene frequency in natural populations and the nature of the immunogens, pathogens or toxins to which they are exposed. The results of the factors responsible for the complex pleiotropic network of the immune system may be indicative of the main protective mechanisms responsible for survival, including those responsible for the aspects of autoimmune pathogenicity.

The advantage of the genetically selected $\mathrm{H}, \mathrm{L}, \mathrm{AIR}_{\mathrm{MAX}}$, and $\mathrm{AIR}_{\mathrm{MIN}}$ mouse line models compared to inbred mice is the availability of individuals genetically homogeneous at the relevant loci controlling a general character but still heterogeneous at other loci, including the MHC antigens, assuring the preservation of the naturally occurring genetic variability in the population study. These features allow the study of the real biological relevance of innate and/or adaptive immune traits and the correlation amongst distinct immunobiological parameters.

In the present study, we evaluated the responsiveness to IRBP immunization in genetically selected mouse lines by measuring both their ability to produce the specific anti-IRBP IgG1 and IgG2a antibody isotypes and their degree of eye pathology during the course of EAU.

\section{Material and Methods}

\section{Animals}

Mouse lineages obtained by bidirectional genetic selection for high $\left(\mathrm{H}_{\text {III }}\right)$ and low $\left(\mathrm{L}_{\text {III }}\right)$ immune responsiveness and for maximal $\left(\mathrm{AIR}_{\mathrm{MAX}}\right)$ and minimal ( $\left.\mathrm{AIR}_{\mathrm{MIN}}\right)$ acute inflammatory reaction were used. $\mathrm{H}_{\text {III }}$ and $\mathrm{L}_{\text {III }}$ animals were obtained from four independent outbred Swiss mouse colonies and selected on the basis of high or low antibody production to flagellar antigens of Salmonellae (26). $\mathrm{AIR}_{\mathrm{MAX}}$ and $\mathrm{AIR}_{\mathrm{MIN}}$ mice were obtained from a Foundation Population de- riving from intercrosses of eight distinct inbred mouse strains (A, DBA-2, P, SWR, CBA, SJL, BALB/c, and C57Bl/6) (23). The selective breeding of these animals for maximal or minimal acute imflammatory response was based on both cellular infiltrate and protein contents. Animals were obtained and maintained at the animal facilities of the Immunogenetics Laboratory of Instituto Butantan. All experiments were performed following the guidelines for animal use approved by the Ethics Committee in Animal Experimentation from the institutions involved in the study and according to the guidelines established by the Association for Research in Vision and Ophthalmology for the care and handling of experimental animals.

\section{Reagents and antibodies}

IRBP was isolated from bovine retinas by concanavalin A-Sepharose affinity chromatography and FPLC $(28,29)$ and stored at $-70^{\circ} \mathrm{C}$. Bordetella pertussis toxin, concanavalin A, bovine serum albumin, and complete Freund adjuvant were purchased from Sigma (St. Louis, MO, USA). Horseradish peroxidase-streptavidin goat anti-IgG1 and antiIgG2a mouse subclasses were purchased from Southern Biotechnologies Associates, Inc. (Birmingham, AL, USA). The hybridomas XMG1.2 and AN18 producers of antimouse interferon- $\gamma($ IFN- $\gamma)$ were a gift from Dr. I. Abrahamsohn (University of São Paulo). Recombinant murine IFN- $\gamma$ and streptavidin-horseradish peroxidase were purchased from BD Pharmingen (San Diego, CA, USA).

\section{Immunization}

$\mathrm{H}_{\mathrm{III}}, \mathrm{L}_{\mathrm{III}}, \mathrm{AIR}_{\mathrm{MAX}}$, and $\mathrm{AIR}_{\mathrm{MIN}}$ mice of both sexes were used at ages ranging from 8 to 12 weeks. Immunizations were performed by injecting simultaneously $50 \mu \mathrm{g}$ IRBP in $0.2 \mathrm{~mL}$ emulsion (v/v) with complete Freund 
adjuvant administered subcutaneously and 1 $\mu \mathrm{g}$ Bordetella pertussis toxin by the intraperitoneal route.

\section{Histology and disease grading}

Eyes were collected 20, 28, and 40 days after immunization, fixed for $1 \mathrm{~h}$ in $4 \%$ sodium phosphate-buffered glutaraldehyde, and transferred to $10 \%$ sodium phosphatebuffered formaldehyde until processing. Fixed and dehydrated tissue was embedded in paraffin and cut into 4- to $6-\mu \mathrm{m}$ sections through the pupillary-optic nerve plane. Six sections cut at different levels were submitted to standard hematoxylin-eosin staining and examined for each eye in a masked fashion. The presence and the extent of the lesions were determined and the severity of EAU was scored on a 0 to 4 scale according to a semi-quantitative system described previously (3). Briefly, the minimal criterion to score an animal as positive by histopathology was inflammatory cell infiltration of the ciliary body, choroid and retina. Progressively higher grades were assigned for the presence of discrete lesions in the tissues such as vasculitis, granuloma formation, retinal folding, and/or detachment and photoreceptor damage.

\section{Assay for IRBP-specific antibody IgG isotypes}

The individual anti-IRBP IgG1 and IgG2a isotype levels were determined by ELISA as previously described (30). Briefly, 96-well microtiter plates (Costar, Cambridge, MA, USA) were coated with IRBP at $1 \mu \mathrm{g} / \mathrm{mL}$ in carbonate/bicarbonate buffer, blocked with bovine serum albumin and incubated with serially diluted serum samples for $1 \mathrm{~h}$ at room temperature. Plates were developed with horseradish peroxidase-conjugated goat anti-mouse IgG1 or with rat anti-mouse IgG2a (diluted 1:2000). The anti-IRBP antibody titers were expressed as $\log _{2}$ of the reciprocal serum dilution giving an absorb- ance value of $20 \%$ of the saturation level.

\section{IFN- $\gamma$ assay}

The draining lymph nodes were collected 20 or 40 days after immunization, teased to a single cell suspension and cultured in Dulbecco's modified Eagle's medium supplemented with $5 \%$ fetal bovine serum (Hyclone, Logan, UT, USA), $10 \mu \mathrm{M}$ 2-mercaptoethanol (Sigma), $2 \mathrm{mM}$ L-glutamine, $0.1 \mathrm{mM}$ vitamins, $1 \mathrm{mM}$ sodium pyruvate, $0.1 \mathrm{mM}$ nonessential amino acids, and $100 \mu \mathrm{g} / \mathrm{mL}$ gentamicin, all purchased from Gibco BRL (Rockville, NY, USA) in a 96-well plate with immobilized anti-CD3 $(1 \mu \mathrm{g} / \mathrm{mL}$; BD/ Pharmingen) for a total of $48 \mathrm{~h}$. IFN- $\gamma$ was determined in the supernatants by sandwich ELISA employing the rat anti-mouse monoclonal antibody system prepared in our own laboratory from culturing the respective hybridomas, purified and biotinylated when used as the detection antibody. High binding 96-well plates (Corning Corporation, Corning, NY, USA) were coated with $50 \mu \mathrm{L}$ of the first antibody diluted in carbonate/bicarbonate buffer, $\mathrm{pH} 9.6$, for $16 \mathrm{~h}$ at $4^{\circ} \mathrm{C}(8 \mu \mathrm{g} /$ $\mathrm{mL}$ anti-IFN- $\gamma$ (XMG1.2)). After incubation, wells were blocked for $2 \mathrm{~h}$ at room temperature with $150 \mu \mathrm{L}$ PBS $/ 0.05 \%$ Tween 20 (Sigma) and 5\% skim milk. Plates were washed three times with PBS $/ 0.05 \%$ Tween 20 and received $50 \mu \mathrm{L}$ of samples or of the recombinant murine IFN- $\gamma$ in 2-fold serial dilutions. After 4-h incubation at room temperature, plates were washed and $50 \mu \mathrm{L}$ of the biotinylated anti-IFN- $\gamma$ (AN18 at $8 \mu \mathrm{g}$ / $\mathrm{mL}$ ) was added and incubated for $2 \mathrm{~h}$ at room temperature. Plates were washed and $80 \mu \mathrm{L}$ streptavidin-peroxidase (Sigma) diluted (1:4000) in PBS was added and incubated for $1 \mathrm{~h}$ at room temperature. Plates were washed again and $100 \mu \mathrm{L}$ of substrate solution $\left(3 \% \mathrm{H}_{2} \mathrm{O}_{2}, 0.5 \mu \mathrm{g} / \mathrm{mL} 2,2\right.$ '-azino-bis(3ethylbenzthiazoline-6-sulfuric acid) in citrate/phosphate buffer, $\mathrm{pH}$ 5.2) was added. The substrate reaction was stopped after 30 
min with $0.2 \mathrm{M}$ citric acid. Absorbance was read at $\lambda 410$ and $490 \mathrm{~nm}$.

\section{Statistical analysis}

EAU scores are reported as the average of both eyes for each animal. Disease scores were analyzed using Snedecor and Cochran's test (31) for linear trend in proportions. Statistical analysis was performed by nonparametric analysis of variance (ANOVA) with Dunn's post-test. Data of the antibody measurements were compared using the unpaired $t$-test or Mann-Whitney test and were considered to be significantly different at $\mathrm{P}<0.05$.

\section{Results}

\section{Susceptibility to EAU}

Susceptibility to EAU was investigated in the genetically selected mouse lineages for high $\left(\mathrm{H}_{\text {III }}\right)$ or low $\left(\mathrm{L}_{\text {III }}\right)$ immune response and for maximal (AIR $\mathrm{AAX}_{\mathrm{MA}}$ ) or minimal $\left(\mathrm{AIR}_{\mathrm{MIN}}\right)$ acute inflammation. Mice were immunized with IRBP and evaluated for the development of EAU 21 days later. The incidence of uveitis, i.e., the number of animals affected with EAU of the total number of injected mice, was $6 / 15$ in the $\mathrm{H}_{\mathrm{III}}$ line and $3 / 9$ in the $\mathrm{L}_{\text {III }}$ line; the EAU in the $\mathrm{AIR}_{\mathrm{MAX}}$ mice was $6 / 13$ whereas $10 / 11$ of $\mathrm{AIR}_{\mathrm{MIN}}$ mice were resistant to the disease - only $9 \%$ developed a mild cell infiltration (Figure 1). The estimated EAU mean grade of cellular infiltration and structural alteration scored on a scale from 0 to 4 among the affected mice was 0.73 for $\mathrm{H}_{\text {III }}, 0.25$ for $\mathrm{L}_{\mathrm{III}}, 0.34$ for $\mathrm{AIR}_{\mathrm{MAX}}$, and 0.09 for $\mathrm{AIR}_{\mathrm{MIN}}$ mice.

\section{Serum IgG1 and IgG2a antibodies to IRBP}

Antibody isotype switching to $\operatorname{IgG} 1$ and IgG2a is promoted mostly by IL-4 and IFN$\gamma$, respectively. Since susceptibility to EAU in inbred mice has been associated with Th1 lymphocytes in the pathogenesis of the dis- ease, we investigated anti-IRBP IgG1 and IgG2a levels in response to IRBP, 21 days after immunization in an attempt to determine the T-cell subset and the cytokine involvement in a more direct fashion than simply measuring IL-4 and IFN- $\gamma$ in vitro. The comparative analysis of IgG isotypes in both genetic selections showed peculiar features. For the $\mathrm{H}_{\mathrm{III}}$ and $\mathrm{L}_{\mathrm{III}}$ lines, as expected, significant interline differences were obtained for both isotypes, mainly for IgG2a antibodies, since the $\mathrm{L}_{\text {III }}$ mice did not produce this subclass in response to IRBP (Figure $2 \mathrm{~A}$ ). Interestingly, $\mathrm{AIR}_{\mathrm{MAX}}$ animals did not produce this anti-IRBP isotype whereas $\mathrm{AIR}_{\text {MIN }}$ mice showed both an IgG1 and IgG2a response to IRBP (Figure 2B). The lack of anti-IRBP IgG2a production in $\mathrm{L}_{\text {III }}$ was observed 40 and 65 days after immunization (data not shown). At the former time $\mathrm{AIR}_{\mathrm{MAX}}$ mice showed detectable IgG2a antibody titers $(3.33 \pm 2.5)$ in response to IRBP. Of note is the fact that in all lineages the $\mathrm{IgG} 2 \mathrm{a} / \mathrm{IgG} 1$

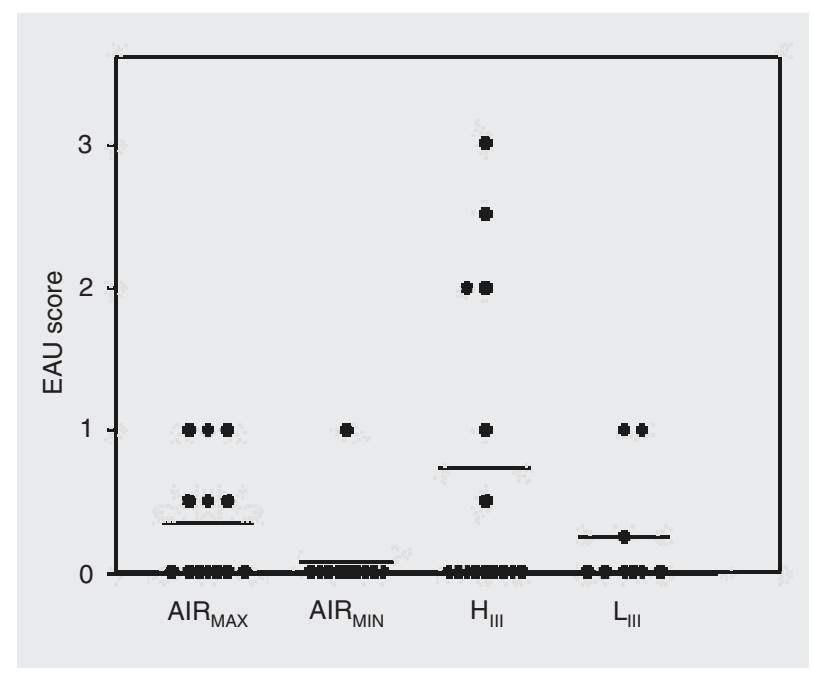

Figure 1. EAU scores for inter-photoreceptor retinoid-binding protein

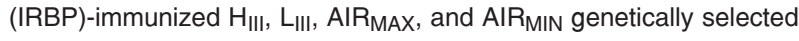
mouse lines. Mice were immunized with $50 \mu \mathrm{g}$ IRBP and $1 \mu \mathrm{g}$ Bordetella pertussis toxin. Eyes were collected for histopathology 21 days after immunization. Scores were assigned on a scale of 0 to 4 according to the extent of inflammation and tissue damage. Each symbol represents one animal (average of both eyes). The horizontal lines indicate the mean for each group. EAU = experimental autoimmune uveitis; AIR $_{M A X}$, AIR $_{\text {MIN }}=$ maximal and minimal acute inflammatory reactions; $H_{\mid I I}, L_{I I I}=$ high and low immune responsiveness. 
ratio was below the " 1 " value, which means that the production of anti-IRBP IgG2a was decreased when compared to the production of IgG1 (Figure 2C).

\section{IFN- $\gamma$ secretion by lymph node cells}

The persistent lack of anti-IRBP IgG2a antibody production in $\mathrm{L}_{\mathrm{III}}$ mice following immunization with IRBP led us to investigate IFN- $\gamma$ production in the supernatants of anti-CD3-stimulated lymph node cell cultures. Cytokine secretion was analyzed in $\mathrm{H}_{\text {III }}$ and $\mathrm{L}_{\text {III }}$ mice 21 days after immunization (Figure 3). As expected, the production of IFN- $\gamma$ was significantly lower in $\mathrm{L}_{\mathrm{III}}$ when compared to high responder animals $(\mathrm{P}<$ $0.01)$. Although $\mathrm{H}_{\mathrm{III}}$ animals were more sus- ceptible to developing disease with higher scores of severity, the incidence of EAU was similar in both $\mathrm{H}_{\mathrm{III}}$ and $\mathrm{L}_{\mathrm{III}}$ lineages, indicating that the participation of IFN- $\gamma$ in the susceptibility to developing moderate levels of EAU may not be so important.

\section{Lack of correlation between IgG2a/IgG1 ratios and EAU scores}

It has been previously shown in susceptible inbred mouse strains that disease severity is directly proportional to their anti-IRBP $\mathrm{IgG} 2 \mathrm{a} / \mathrm{IgG} 1$ ratios. Here we investigated the relationship between these two phenotypes. The present results in non-inbred mouse strains clearly demonstrate the absence of correlation between $\mathrm{IgG} 2 \mathrm{a} / \mathrm{IgG} 1$ ratio and
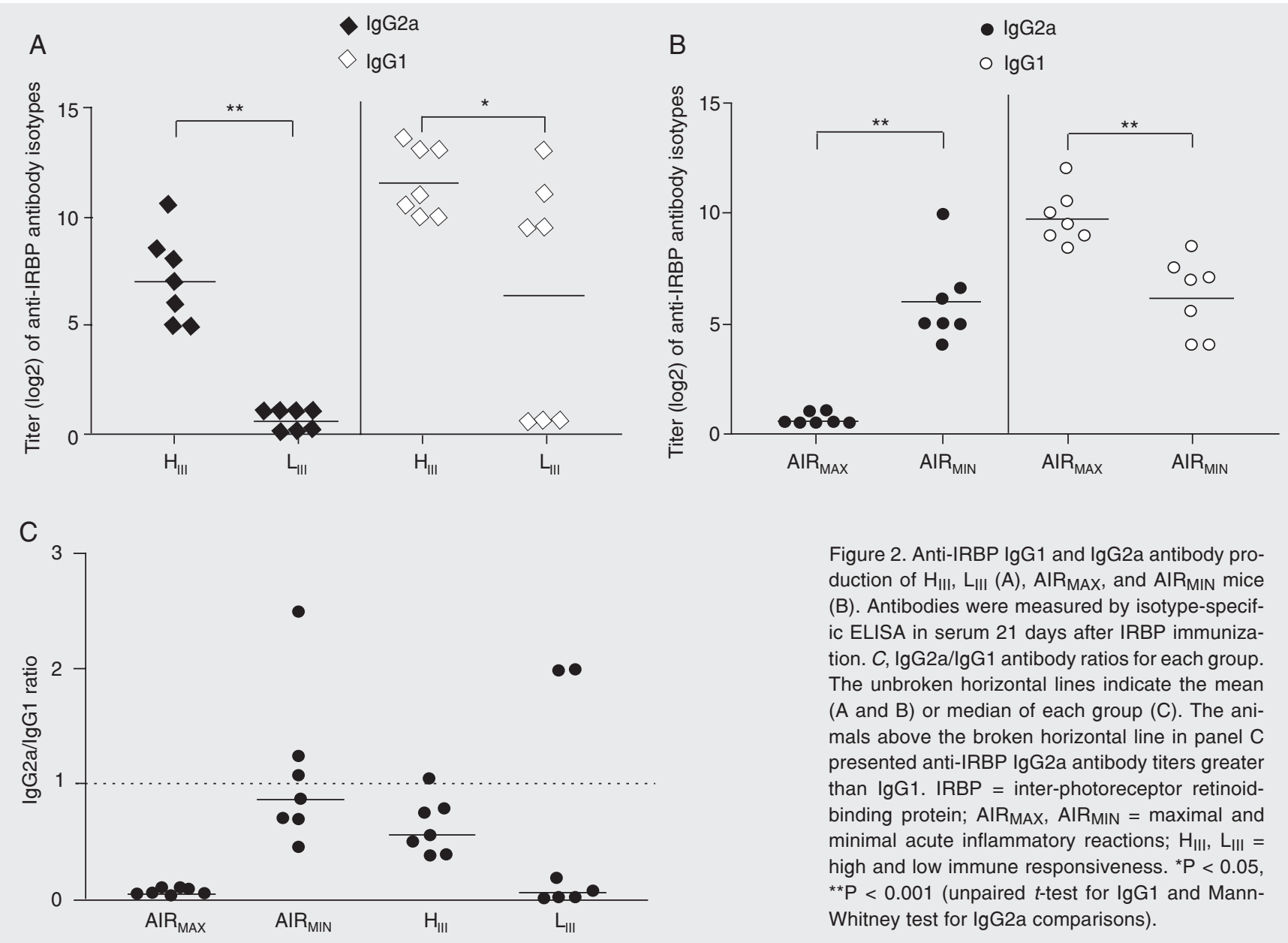

Figure 2. Anti-IRBP IgG1 and IgG2a antibody production of $H_{I I I}, L_{I I I}(A)$, AIR $R_{M A X}$, and AIR MIN mice (B). Antibodies were measured by isotype-specific ELISA in serum 21 days after IRBP immunization. $C$, IgG2a/lgG1 antibody ratios for each group. The unbroken horizontal lines indicate the mean ( $A$ and $B$ ) or median of each group (C). The animals above the broken horizontal line in panel $C$ presented anti-IRBP IgG2a antibody titers greater than IgG1. IRBP = inter-photoreceptor retinoidbinding protein; $A I R_{M A X}, A I R_{M I N}=$ maximal and minimal acute inflammatory reactions; $\mathrm{H}_{|| l}, \mathrm{~L}_{\| I}=$ high and low immune responsiveness. ${ }^{*} P<0.05$, ${ }^{\star *} \mathrm{P}<0.001$ (unpaired $t$-test for IgG1 and MannWhitney test for IgG2a comparisons). 
susceptibility to EAU as well as the severity of disease, as evidenced by the $\mathrm{H}_{\mathrm{III}}, \mathrm{L}_{\mathrm{III}}$, $\mathrm{AIR}_{\mathrm{MAX}}$, and $\mathrm{AIR}_{\mathrm{MIN}}$ profiles (Figure 4).

\section{Discussion}

The design of the present study was based on an alternative concept for the investigation of autoimmune uveitis in mice. Human uveitis is a complex disease in which the genetic background plays a significant role even when the same entity is under study (32). The goal of an animal model of human disease is to be as closely similar to the human entity as possible, and for this reason we set out to establish EAU in a non-inbred mouse population. Four genetically selected lines of mice resulted in the convergent fixation of alleles affecting the high or low antibody or inflammatory responses regarding

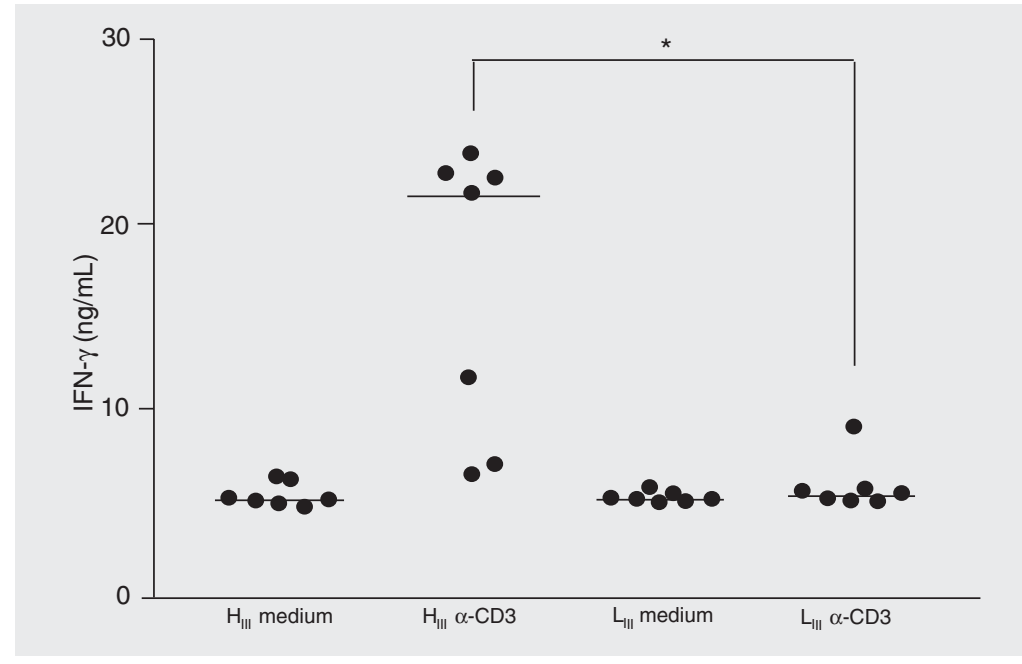

Figure 3. IFN- $\gamma$ synthesis in $\mathrm{H}_{|| \mid}$and $\mathrm{L}_{||}$mice. The cytokine was measured in the supernatants of activated cell cultures from individual mice. Draining lymph node cells were collected 21 days after immunization and stimulated or not with anti-CD3 antibody for $48 \mathrm{~h}$. The horizontal lines indicate the means. IFN- $\gamma=$ interferon- $\gamma$; AIR $_{\text {MAX }}$, AIR $\mathrm{R}_{\mathrm{MIN}}=$ maximal and minimal acute inflammatory reactions; $\mathrm{H}_{\| I}, L_{\mid I I}=$ high and low immune responsiveness. ${ }^{*} P<0.01$ (Mann-Whitney test).
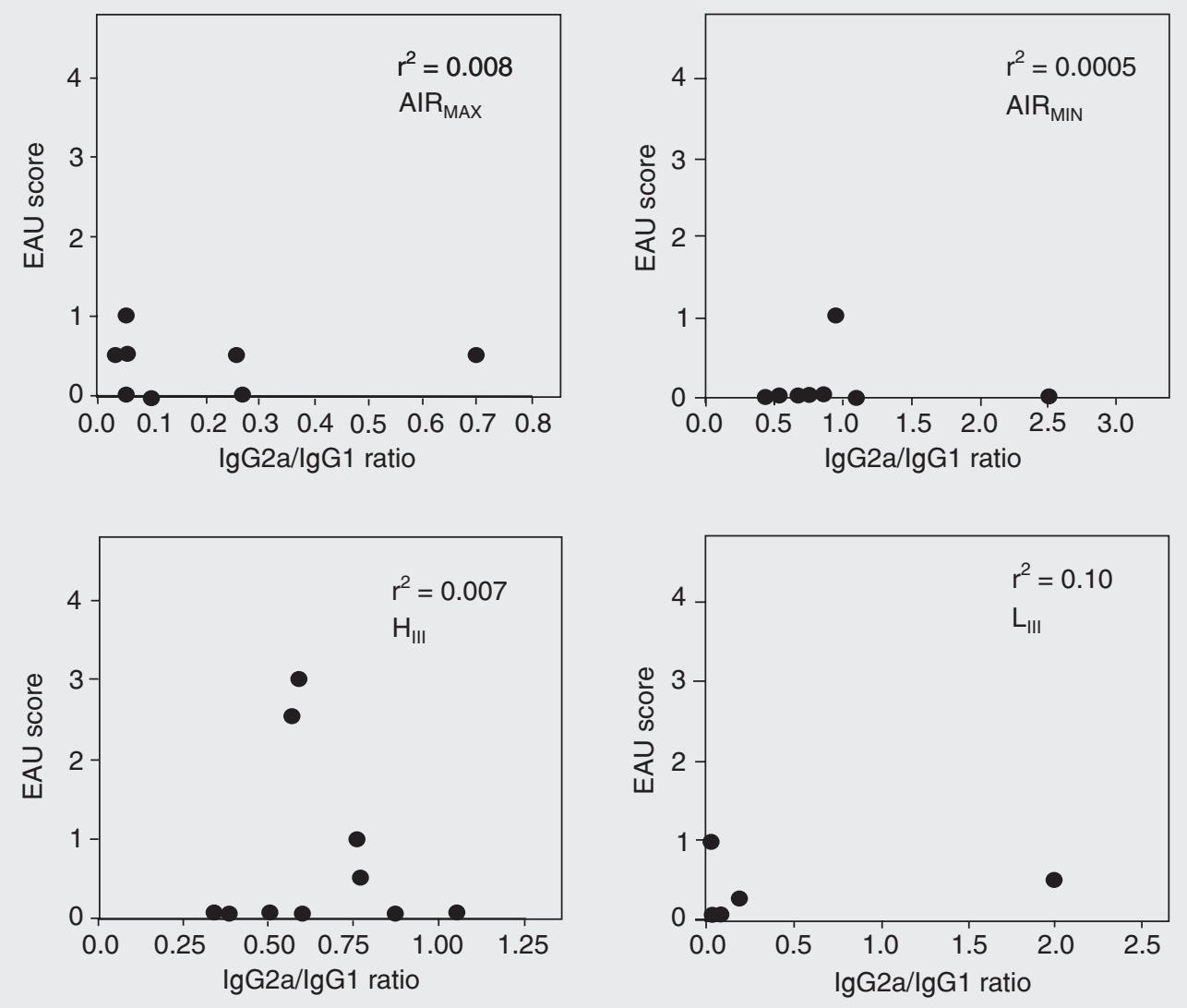

Figure 4. Absence of correlation between individual EAU scores and anti-IRBP IgG2a/lgG1 antibody ratios. Anti-IRBP IgG2a/ IgG1 ratios were plotted individually against the EAU scores. The correlation line was plotted by the linear curve fitting. EAU = experimental autoimmune uveitis; AlR $_{\text {MAX }}, A I R_{\text {MIN }}=$ maximal and minimal acute inflammatory reactions; $H_{\mid I I}, L_{I I I}=$ high and low immune responsiveness. 
the innate and/or acquired immune compartments. This approach allows the study of the disease in populations that have been selected for definite immunobiological traits but still, at least in part, heterogeneous with regards to the rest of their genome, thus better resembling the human population. Here, we investigated EAU development and the anti-IRBP IgG1 and IgG2a antibody production in $\mathrm{H}_{\mathrm{III}}, \mathrm{L}_{\mathrm{III}}$, $\mathrm{AIR}_{\mathrm{MAX}}$, and $\mathrm{AIR}_{\mathrm{MIN}}$ mice. It was demonstrated that in these mice, unlike in inbred strains, susceptibility to experimental autoimmune uveitis does not correlate with the production of anti-IRBP IgG2a isotype.

The data indicate that the amount of antiIRBP IgG1 antibody was similar among the lines during the period evaluated and titerwise higher than the anti-IRBP IgG2a in all selected mouse strains, with the exception of $\mathrm{AIR}_{\mathrm{MIN}}$ mice that expressed the same titers for both $\mathrm{IgG} 1$ and $\mathrm{IgG} 2 \mathrm{a}$ isotypes 21 days after IRBP administration. The levels of antiIRBP IgG2a subclass were nearly undetectable in $\mathrm{L}_{\mathrm{III}}$ mice. In other experiments serum was tested for the presence of $\operatorname{IgG1}$ and IgG2a antibodies in response to IRBP 40 and 65 days after immunization. It was intriguing to notice that $\mathrm{L}_{\mathrm{III}}$ mice did not produce IRBP-specific IgG2a antibody whereas the other mouse lines responded with high antibody titers although always lower when compared to IgG1. This peculiar pattern seems to be dependent on the isotype-restricted regulatory effect related to the immunization procedure used during the selective breeding process to which the parental animals were submitted to develop the lineages. In fact, a similar picture in the $\operatorname{IgG} 2$ a profile of the $\mathrm{H}_{\mathrm{III}}$ and $\mathrm{L}_{\mathrm{III}}$ line was observed after immunization with Salmonella flagellar and somatic antigens, both present during the selective process (26). Interestingly, all lines exhibited IgG2a/IgG1 ratios below "1", irrespective of the susceptibility to the disease, suggesting that under any circumstances antiIRBP IgG2a levels were higher than IgG1 antibody. Histopathologic examination of the eyes after antigen administration showed disorganization of the retinal architecture in 40 to $50 \%$ of the animals of the $\mathrm{AIR}_{\mathrm{MAX}}, \mathrm{H}_{\mathrm{III}}$, and $\mathrm{L}_{\mathrm{III}}$ strains. AIR $\mathrm{MIN}_{\mathrm{MIN}}$ mice were resistant to the development of EAU with only 1 affected individual of 11. In a similar study performed with high responder mice selected for heterologous erythrocytes (19), the socalled Biozzi ABH mice, a higher percentage of individuals susceptible to uveoretinitis and low levels of antigen-specific IgG2a subclass were observed (33). Our data support previously published results on the subject.

The balance between Th1 and Th 2 cells and its role in determining the outcome of the immune response to the uveitogenic proteins has been an issue for some time. It has been shown that mouse strains susceptible to EAU polarize their response against the retinal antigen towards a type 1 response, consequently enhancing the production of antiuveitogen IgG2a antibody, an IFN- $\gamma$-induced isotype, even after EAU onset. In contrast, a type 2 response and a dominant $\mathrm{IgG} 1$ profile have been associated with a resistant phenotype (11). This paradigm does not hold true in these genetically selected non-inbred lines of mice, suggesting it may be a consequence of the inbreeding process by carrying together with the quantitative trait loci that code for susceptibility, those that control isotype switching to IgG1 and IgG2a. The differential result obtained in outbred mice may explain why only a percentage of patients with autoimmune uveitis develop a cytokine profile similar to the one described in inbred mice, whereas all patients present a similar inflammatory reaction (34). Continued studies on these strains will help associate specific clinical features such as retinal detachment with sustained patterns of immune response to ocular antigens.

The data presented here show a predominant anti-IRBP IgG1 antibody response in the serum of $\mathrm{AIR}_{\mathrm{MAX}}$ and $\mathrm{L}_{\mathrm{III}}$ mice 21 days after IRBP immunization. Interestingly, this 
response did not correlate with a resistant phenotype, since $27 \%$ of $\mathrm{L}_{\mathrm{III}}$ mice and $40 \%$ of $\mathrm{AIR}_{\mathrm{MAX}}$ mice were sick after immunization with IRBP. On the other hand, AIR MIN animals showed enhanced anti-IRBP IgG2a antibody titers compared to $\mathrm{AIR}_{\mathrm{MAX}}$ mice but were resistant to the disease. Another interesting feature was the observation that $\mathrm{L}_{\text {III }}$ mice did not produce IFN- $\gamma$ even after anti-CD3 stimulation. This event was compatible with the lack of production of antiIRBP $\operatorname{IgG} 2 \mathrm{a}$ isotype after immunization. Based on these data, one could expect a resistant phenotype for $\mathrm{L}_{\mathrm{III}}$ regarding the development of uveitis since the disease has been correlated with a dominant type- 1 response (11). In fact, in high responder animals the production of IFN- $\gamma$ seems to correlate with susceptibility since these animals develop a milder disease with an incidence of EAU in almost $50 \%$ of the population. Although AIR $_{\text {MAX }}$ mice do not produce IRBP-specific IgG2a 21 days after immunization, over longer periods of time these animals were able to secrete this isotype, differently from $\mathrm{L}_{\mathrm{III}}$ mice. Still, this unbalanced situation between the two isotypes in favor of anti-IRBP IgG1 antibody did not protect $\mathrm{AIR}_{\mathrm{MAX}}$ from developing EAU. The development of EAU in the context of lack of secretion of IFN- $\gamma$ has already been shown. Mice treated with anti-IFN- $\gamma$ antibody develop EAU and this feature was also observed in some resistant strains of mice after systemic depletion of this cytokine (35). Other studies have shown that IFN- $\gamma$-deficient mice are highly susceptible to developing EAU after immunization with whole IRBP (36) or with the major uveitogenic human peptide 1-20 (37) and in the latter case the resulting disease is significantly more severe when compared to wild-type controls. The cytokine profile in the supernatants of these animals lacking IFN- $\gamma$ was skewed toward a Th2-like response, showing an up-regulation of IL-5. Cellular infiltrates contained significantly more eosino- phils compared to their wild-type littermates. In our experiments, although we did not look at the mechanisms involved in the development of EAU in low IFN- $\gamma$-producing animals such as AIR $_{\text {MAX }}$ and $\mathrm{L}_{\mathrm{III}}$, we cannot rule out the possibility of a deviant immune response in these mice.

For both antigen-specific IgG1 and $\mathrm{IgG} 2 \mathrm{a}$ antibodies, analysis of variance supported the importance of multigenic factors regulating the adaptive response to IRBP. Moreover, based on the distinct $\mathrm{H}-2$ genes of the four mouse lines and the similarities of the EAU scores, especially between the $\mathrm{AIR}_{\mathrm{MAX}}$ and $\mathrm{L}_{\mathrm{III}}$ strains, no specific MHC allele seems to be crucial for the development of the disease, as it is in inbred strains of mice. However, we must point out that the $\mathrm{L}_{\mathrm{III}}$ mice are $\mathrm{H}-2^{\mathrm{z}}, \mathrm{H}_{\mathrm{III}}$ are $\mathrm{H}-2^{\circ 3}(3,38), \mathrm{AIR}_{\text {MAX }}$ are predominantly $\mathrm{H}-2^{\mathrm{b}}$, and in $\mathrm{AIR}_{\mathrm{MIN}}$ mice the $\mathrm{H}-2^{\mathrm{d}}$ and $\mathrm{H}-2^{\mathrm{k}}$ haplotypes are more prevalent. Therefore, we suggest that the genetic control of the adaptive immune characteristics during the autoimmune process in EAU is polygenic, since the interline variances were always higher than the intraline ones and there were continuous distributions among individuals.

The evaluation of the development of the disease in $\mathrm{AIR}_{\mathrm{MAX}}$ and $\mathrm{AIR}_{\mathrm{MIN}}$ mice can also be considered from the viewpoint of the inflammatory potential that these lines present in response to distinct pathogens, immunogens and chemical agents. In uveitis, damage to the eye is a consequence of the recruitment of lymphocytes, macrophages and polymorphonuclear cells. The lymphocyte population that migrates to the eye is constituted of both retinal antigen-specific lymphocytes and "non-specific cells" $(39,40)$. The fact that $\mathrm{AIR}_{\text {MIN }}$ mice are resistant to EAU suggests that the low intrinsic inflammatory capacity of these animals might be due to the fact that these mice were selected based on lower numbers of cells migrating to the inflammatory site compared to the $\mathrm{AIR}_{\mathrm{MAX}}$ mice. 
In conclusion, our data suggest that the mechanisms involved in the resistance or susceptibility to EAU development involve polymorphic intervention of independent multigenic immunobiological factors, which are very important for the chronic nature of uveitis development.

\section{References}

1. Gery I, Mochizuki M \& Nussenblatt RB (1986). Retinal specific antigens and immunopathogenic processes they provoke. Progress in Retinal and Eye Research, 5: 75-109.

2. Caspi RR, Roberge FG, Chan CC et al. (1988). A new model of autoimmune disease: experimental autoimmune uveoretinitis induced in mice with two different retinal antigens. Journal of Immunology, 140: 1490-1495.

3. Wacker WB, Donoso LA, Kalsow CM et al. (1977). Experimental allergic uveitis. Isolation, characterization, and localization of a soluble uveitopathogenic antigen from bovine retina. Journal of Immunology, 119: 1949-1958.

4. Hankey DJ, Lightman SL \& Baker D (2001). Interphotoreceptor retinoid binding protein peptide-induced uveitis in B10.RIII mice: characterization of disease parameters and immunomodulation. Experimental Eye Research, 72: 341-350.

5. Caspi RR, Silver PB, Chan CC et al. (1996). Genetic susceptibility to experimental autoimmune uveoretinitis (EAU) in the rat is associated with an elevated Th1 response. Journal of Immunology, 157: 2668-2675.

6. Liblau RS, Singer SM \& McDevitt HO (1995). Th1 and Th2 CD4+ T cells in the pathogenesis of organ-specific autoimmune disease. Immunology Today, 16: 34-38.

7. Rizzo LV, Silver P, Wiggert B et al. (1996). Establishment and characterization of a murine $\mathrm{CD} 4^{+} \mathrm{T}$ cell line and clone that induce experimental autoimmune uveoretinitis in B10.A mice. Journal of Immunology, 156: 1654-1660.

8. Caspi RR (1994). Th1 and Th2 lymphocytes in experimental autoimmune uveoretinitis. In: Whitcup SM, Nussenblatt RB, Caspi RR et al. (Editors), Advances in Ocular Immunology. International Congress Series, Elsevier Science Publishers, Amsterdam, The Netherlands, 55.

9. Saoudi A, Kuhn J, Huygen K et al. (1993). Th2 activated cells prevent experimental autoimmune uveoretinitis, a Th1-dependent autoimmune disease. European Journal of Immunology, 23: 30963103.

10. Chan CC, Mochizuki M, Nussenblatt RB et al. (1985). T-lymphocyte subsets in experimental autoimmune uveitis. Clinical Immunology and Immunopathology, 35: 103-110.

11. Sun B, Rizzo LV, Sun SH et al. (1997). Genetic susceptibility to experimental autoimmune uveitis involves more than a predisposition to generate a $\mathrm{T}$ helper-1-like or a $\mathrm{T}$ helper-2-like response. Journal of Immunology, 158: 1004-1011.

12. Bossu P, Singer GG, Andres $P$ et al. (1993). Mature CD4+ T lymphocytes from MRL/lpr mice are resistant to receptor-mediated tolerance and apoptosis. Journal of Immunology, 151: 7233-7239.

13. Chu JL, Drappa J, Parnassa A et al. (1993). The defect in Fas mRNA expression in MRL/Ipr mice is associated with insertion of the retrotransposon, ETn. Journal of Experimental Medicine, 178: 723730.

14. Drappa J, Brot N \& Elkon KB (1993). The Fas protein is expressed at high levels on CD4+CD8+ thymocytes and activated mature lymphocytes in normal mice but not in the lupus-prone strain, MRL Ipr/ Ipr. Proceedings of the National Academy of Sciences, USA, 90: 10340-10344.

15. Broekhuyse RM, Kuhlmann ED \& Winkens HJ (1993). Experimental autoimmune anterior uveitis (EAAU): induction by melanin antigen and suppression by various treatments. Pigment Cell Research, 6: 1-6.

16. Griffith TS, Yu X, Herndon JM et al. (1996). CD95-induced apoptosis of lymphocytes in an immune privileged site induces immunological tolerance. Immunity, 5: 7-16.

17. Griffith TS, Brunner T, Fletcher SM et al. (1995). Fas ligand-induced apoptosis as a mechanism of immune privilege. Science, 270: 11891192.

18. Egwuagu CE, Charukamnoetkanok P \& Gery I (1997). Thymic expression of autoantigens correlates with resistance to autoimmune disease. Journal of Immunology, 159: 3109-3112.

19. Silver PB, Rizzo LV, Chan CC et al. (1995). Identification of a major pathogenic epitope in the human IRBP molecule recognized by mice of the H-2r haplotype. Investigative Ophthalmology and Visual Science, 36: 946-954.

20. Caspi RR, Grubbs BG, Chan C-C et al. (1992). Genetic control of susceptibility to experimental autoimmune uveoretinitis in the mouse model. Concomitant regulation by MHC and non-MHC genes. Journal of Immunology, 148: 2384-2389.

21. Caspi RR (1992). Immunogenetic aspects of clinical and experimental uveitis. Regional Immunology, 4: 321-330.

22. Biozzi G, Mouton D, Sant'Anna OA et al. (1979). Genetics of immunoresponsiveness to natural antigens in the mouse. Current Topics in Microbiology and Immunology, 85: 31-98.

23. Ibañez OM, Stiffel C, Ribeiro OG et al. (1992). Genetics of nonspecific immunity: I. Bidirectional selective breeding of lines of mice endowed with maximal and minimal inflammatory responsiveness. European Journal of Immunology, 22: 2555-2563.

24. da Silva AC, Souza KW, Machado RC et al. (1998). Genetics of immunological tolerance: I. Bidirectional selective breeding of mice for oral tolerance. Research in Immunology, 49: 151-161.

25. da Silva MF, da Costa SC, Ribeiro RC et al. (2001). Independent genetic control of B- and T-cell tolerance in strains of mouse selected for extreme phenotypes of oral tolerance. Scandinavian Journal of Immunology, 53: 148-154.

26. Siqueira M, Bandieri A, Reis MS et al. (1976). Selective breeding of mice for antibody responsiveness to flagellar and somatic antigens of salmonellae. European Journal of Immunology, 4: 241-249.

27. Boyartchuk V \& Dietrich W (2002). Genetic dissection of host immune response. Genes and Immunity, 3: 119-122.

28. Pepperberg DR, Okajima TL, Ripps $\mathrm{H}$ et al. (1991). Functional properties of interphotoreceptor retinoid-binding protein. Photochemistry and Photobiology, 54: 1057-1060.

29. Pepperberg DR, Okajima TL, Wiggert B et al. (1993). Interphotore- 
ceptor retinoid-binding protein (IRBP): molecular biology and physiological role in the visual cycle of rhodopsin. Molecular Neurobiology, 7: 61-85.

30. Rizzo LV, DeKruyff RH, Umetsu DT et al. (1995). Regulation of the interaction between Th1 and Th2 cell clones to provide help for antibody production in vivo. European Journal of Immunology, 25: 708-716.

31. Snedecor GW \& Cochran WG (1967). Statistical Methods. Iowa State University Press, Ames, IA, USA, 248.

32. Tugal-Tutkun I, Onal S, Altan-Yaycioglu R et al. (2004). Uveitis in Behcet disease: an analysis of 880 patients. American Journal of Ophthalmology, 138: 373-380.

33. Hankey JR, Nickerson JM, Donoso LA et al. (2001). Experimental autoimmune uveoretinitis in mice (Biozzi ABH and NOD) expressing the autoimmune-associated $\mathrm{H}-2 \mathrm{~A}^{97}$ molecule: identification of a uveitogenic epitope. Journal of Neuroimmunology, 118: 212-222.

34. Singh VK \& Rai G (2001). Cytokines in posterior uveitis: an update. Immunologic Research, 23: 59-74.

35. Caspi RR, Chan CC, Grubbs BG et al. (1994). Endogenous sys- temic IFN-gamma has a protective role against ocular auto-immunity in mice. Journal of Immunology, 152: 890-899.

36. Jones SL, Rizzo LV, Agarwal RK et al. (1997). IFN- $\gamma$-deficient mice develop experimental autoimmune uveitis in the context of a deviant effector response. Journal of Immunology, 158: 5997-6005.

37. Avichezer D, Chan C-C, Silver PB et al. (2000). Residues 1-20 of IRBP and whole IRBP elicit different uveitogenic and immunological responses in interferon gamma deficient mice. Experimental Eye Research, 71: 111-118.

38. Frangoulis B, Mouton D, Sant'Anna OA et al. (1990). H-2 typing of mice genetically selected for high or low antibody production. Immunogenetics, 31: 389-392.

39. Gritz DC, Montes C, Atalla LR et al. (1991). Histochemical localization of superoxide production in experimental autoimmune uveitis. Current Eye Research, 10: 927-931.

40. Chan C-C, Caspi RR, Roberge FG et al. (1988). Dynamics of experimental autoimmune uveoretinitis induced by adoptive transfer of S-antigen-specific T cell line. Investigative Ophthalmology and Visual Science, 29: 411-418. 